\title{
Knowledge of Emergency Contraceptive Pills among Hungarian Women Presenting for Induced Abortion or Seeking Emergency Contraception
}

Was wissen Frauen, die sich in Ungarn zu einem Schwangerschaftsabbruch oder zur

Verschreibung der Pille danach in einer Klinik vorstellen, von der Notfallkontrazeption?

Authors

Affiliations
Z. Kozinszky ${ }^{1}$, I. Devosa ${ }^{2}$, Z. Fekete ${ }^{3}$, D. Szabó ${ }^{3}$, J. Sikovanyecz ${ }^{3}$, N. Pásztor ${ }^{3}$, A. Keresztúri ${ }^{3}$

${ }^{1}$ Department of Obstetrics and Gynecology, Blekinge Hospital, Karlskrona, Sweden

${ }^{2}$ College of Kecskemét, Teacher Training Faculty, Health Science and Health Promotion Research Group,

Hungary, Kecskemét, Hungary

${ }^{3}$ Department of Obstetrics and Gynaecology, University of Szeged, Szeged, Hungary
Key words

- emergency contraceptive pill

- women requesting pregnancy termination

Schlüsselwörter

- Pille danach

- Frauen, die Abtreibung verlangen received $\quad 15.12 .2013$

revised 20.3.2016

accepted 30.3.2016

Bibliography

DOI http://dx.doi.org/

10.1055/s-0042-105746

Geburtsh Frauenheilk 2016; 76 :

978-982 @ Georg Thieme

Verlag KG Stuttgart · New York . ISSN 0016-5751

Correspondence

Dr. Zoltan Kozinszky,

M.D., Ph.D.

Department of Obstetrics

and Gynecology

Blekinge Hospital

Lasarettsvägen

37181 Karlskrona

Sweden

kozinszky@gmail.com

\section{Abstract}

$\nabla$

Aim: To compare the differences in contraceptive characteristics and the knowledge of emergency contraception (ECP) among women who used ECP after unprotected intercourse and those who sought an abortion.

Methods: A questionnaire survey was conducted in a Hungarian university hospital among women for whom ECP was prescribed after unprotected intercourse ( $n=940$ ) as well as women who presented for the termination of pregnancy $(n=1592)$ between January 1, 2005 and November 20, 2006. Their knowledge of ECP and their experience with and attitudes toward ECP use were targeted.

Results: The availability of ECP was well known (87.9\%), but it was still greatly underutilized: applied by only 13 of the 1592 women who resorted to abortion. Primarily, the ECP group consisted of those who experienced a condom failure significantly more often (odds ratio $[\mathrm{OR}]=4.1$ ), followed by those cases where ECP applications was a consequence of not using any kind of contraception $(\mathrm{OR}=3.8)$. Fewer than one third $(32 \%)$ of the abortion seekers had previously used ECP, and only one fifth knew how to obtain it. Appropriate awareness of ECP was influenced by information obtained from health-care providers (adjusted odds ratio $[A O R]=3.93$ ) or school education (AOR = 1.82).

Conclusions: More thorough education is needed to provide a deeper knowledge of ECP use during contraceptive counseling for women seeking abortion, including those contraceptive mishaps where unintended pregnancy can be prevented by ECP.

\section{Zusammenfassung \\ $\nabla$}

Ziel: Diese Arbeit untersucht einerseits das Wissen der Frauen um die „Pille danach“, andererseits vergleicht diese Studie die verschiedenen Verhütungsmethoden, welche die Frauen, die um die „Pille danach“ oder Abort ansuchen, verwenden.

Methodik: Es wurde eine Umfrage an einer ungarischen Universitätsklinik durchgeführt. Gruppe 1 umfasste Frauen, welche die „Pille danach“ erhalten hatten $(n=940)$, die 2 . Gruppe setzte sich aus Frauen zusammen, die sich für einen Schwangerschaftsabbruch entschieden hatten $(n=1592)$. Die Umfrage wurde zwischen 01.01.2005 und 20.11.2006 durchgeführt. Beide Gruppen wurden gezielt nach deren Erfahrungen, Einstellungen und Kenntnissen über die „Pille danach“ befragt. Ergebnisse: Die Notfallverhütung ist zu einem hohen Grad bekannt (87,9\%), wird aber nur selten verwendet. Nur 13 von 1592 Frauen, die eine Abtreibung wünschten, verwendeten diese Methode. Die Gruppe der Frauen, welche die Pille danach vorgezogen hatten, benutzen häufiger Kondome (Odds Ratio $[\mathrm{OR}]=4,1$ ) oder verwendeten keine Präventivmittel $(\mathrm{OR}=3,8)$. Weniger als ein Drittel der Frauen, die einen Schwangerschaftsabbruch wünschten, hatten zuvor die Notfallverhütung versucht. Nur ein Fünftel aller Frauen in dieser Untersuchung weiß, wo man die „Pille danach“ bekommen kann. Frauen, die gut über die Existenz, Anwendung und Beschaffung informiert sind, haben diese Information von Gesundheitsdienstleistern (Adjust Odds Ratio $[\mathrm{AOR}]=3,93$ ) oder der Schule (AOR = 1.82).

Schlussfolgerung: Bessere Ausbildung der Frauen in Bezug auf die Existenz, Anwendung und Beschaffung der Pille danach könnte die Rate der Aborte senken. 


\section{Introduction}

\section{$\nabla$}

A reduction of the unintended pregnancy rate is a national health priority. Abortion rate (i.e. the number of abortions per 1000 women of reproductive age) in Hungary fell significantly from 35.6 in 1990 to 19.1 in 2006 in Hungary [1]; the corresponding data are lowest in Germany and Switzerland worldwide $(\approx 7$ per 1000 women in 2008) [2,3]. Although more than every fourth pregnancy (28.2\%) in Hungary leads to abortion [1], emergency contraception (ECP) has not yet been introduced as non-prescription medication, highlighting the need for comprehensive medical counseling. The annual number of prescriptions in Hungary is quite low, amounting to only approximately 25000 (annual ECP use per capita: 0.0025) (in-house statistics of the pharmaceutical company Richter, whereas ECP is prescribed in Germany far more frequently, totaling about 400000 prescriptions per year [annual ECP use per capita: 0.00491]) [1,3]. Although ECP is used to reduce the risk of pregnancy after unprotected intercourse [4, 5], its OTC availability did not reduce abortion rate in the UK [6]. Awareness of ECP is not sufficient to use it [7]: recognition of the need and the knowledge of how to receive it are also important factors. As far as the literature is concerned, there have been relatively few analyses of the factors which promote the use of ECP rather than simply not applying any backup contraceptive method after unprotected sexual contact. The purpose of this study was to determine the factors influencing "the appropriate knowledge" [8] (i.e. the awareness of how to receive ECP and by what time it should be taken following unprotected intercourse) through a comparison of ECP users with those who requested abortion, in terms of contraceptive knowledge, attitude and specification.

\section{Materials and Methods}

\section{Participants}

In 2006, 940 (78.0\%) out of 1205 women taking ECP and 1592 (88.7\%) out of 1794 consecutively recruited women requesting abortion voluntarily completed an anonymous multiple choice questionnaire at a university hospital in Hungary.

\section{Data collection}

This structured, self-reported Hungarian-language questionnaire recorded the age, type of residence, marital status, level of education, number of previous pregnancy terminations and the number of live births of the recruited participants, and information about their contraceptive use in the cycle when ECP had been used or in the cycle resulting in their procured abortion (at the time of conception). The questions about ECP dealt with their awareness of ECP (i.e. whether they know that ECP exists), their knowledge of the time limit (i.e. an ECP can be applied within 3 days after an unprotected sexual intercourse), the way to obtain ECP (i.e. through a prescription provided by a gynecologist/general practitioner [GP]), previous ECP use and intended prospective use of ECP. In Hungary, ECP containing levonorgestrel was available by prescription during the time of the study. Method failures were considered according to WHO guidelines on ECP use $[4,5]$ in the ECP group, and contraceptive method use is distinguished as patient and method failures (when appropriate) in the termination of pregnancy sample. Patient failure was justified when condom broke or slipped or the patient reported ejac- ulation in the vagina or miscalculation of the abstinence period or missing to take pills in time or delay in placing the vaginal ring.

\section{Statistical analysis}

Data were entered and analyzed by means of the statistical software package SPSS 17.0 (SPSS Inc., Chicago, IL, USA). Univariate comparisons were assessed by the unpaired t-test and the $\mathrm{X}^{2}$ test, while a logistic regression model was constructed to evaluate the factors simultaneously influencing "the appropriate knowledge" [8] of ECP use. P-values $<0.05$ were considered to be statistically significant. The medical ethics committee of the University of Szeged had approved the study. Informed consent was obtained from all participating women and from the legal guardians of minors under 18 years of age. The study was carried out according to the principles of the Declaration of Helsinki.

\section{Results \\ $\boldsymbol{\nabla}$ \\ Sociodemographic data and contraceptive use}

The sociodemographic characteristics and contraceptive methods of the respondents in the ECP group and women requesting abortion are detailed in $\triangle$ Table 1. Women who sought abortion were significantly older than ECP users (median age in the ECP group was 22 vs. 29 years in the abortion group) and a larger proportion of them lived with a spouse $(4.6 \%$ in the ECP group vs. $49.6 \%$ in the abortion group, $\mathrm{p}<0.001)$. Significantly more urban residents used ECP $(80.4 \%$ in the ECP group vs. $59.9 \%$ in the abortion group, $\mathrm{p}<0.001)$, whereas the two groups were similarly educated. The percentage of women having at least one child was significantly higher in those seeking abortion than in the ECP group (16.7\% in the ECP group vs. $35.0 \%$ in the abortion group, $\mathrm{p}<0.001)$. Similary, the number of previous abortions was significantly higher in their population compared to the ECP group (19.5\% in the ECP group vs. 55.6\% in the abortion group, $\mathrm{p}<0.001)$. More ECP users' partners wore a condom $(59.4 \%$ in the ECP group vs. $26.4 \%$ in the abortion group, $\mathrm{p}<0.001$ ) at the time of conception, whereas combined oral contraceptives were almost equally used in the two groups (11.0\% in the ECP group vs. $11.9 \%$ in the abortion group, $\mathrm{p}>0.05$ ). More respondents in the abortion group had experienced problems with periodic abstinence techniques (3.0\% in the ECP group vs. $28.0 \%$ in the abortion group, $\mathrm{p}<0.001$ ) or withdrawal $(11.7 \%$ in the ECP group vs. $23.1 \%$ in the abortion group, $\mathrm{p}<0.001)$. Contraceptive ring, patch and injection, intrauterine device, spermicides and vaginal douche were not represented among those who used ECP, but these methods were employed by a small number of the women who sought abortion. Only 13 women who requested abortion $(0.8 \%)$ had used ECP unsuccessfully after the contraceptive mishap. The male partners of seven (54\%) used a condom and 3 (23\%) of them had not had recourse to any method for occasional intercourse, 2 (15.4\%) of them had experienced failure while taking OC, and one (7.7\%) of them had a coitus interruptus failure.

\section{Knowledge, attitudes, and use of ECP}

- Table 2 presents an overview of the ECP-related questions. An important finding was that the study groups had applied the ECP similarly at an early stage (33.0\% in the ECP group vs. $31.5 \%$ in the abortion group, $\mathrm{p}>0.05$ ), though awareness was lower among women who sought abortion ( $\mathrm{p}<0.001)$. As expected, knowledge of correct timing (77.9\% in the ECP group vs. $59.0 \%$ in the abortion group, $\mathrm{p}<0.001)$ and the ability to obtain ECP $(78.9 \%$ in the 
Table 1 Sociodemographic and contraceptive characteristics of women attending for an ECP prescription (ECP group, $\mathrm{n}=940$ ) or requesting pregnancy termination ( $n=1592$ ) at the Department of Obstetrics and Gynecology, University of Szeged, Hungary (January 1, 2005 - November 20, 2006).

\begin{tabular}{|c|c|c|c|c|c|c|}
\hline & \multicolumn{2}{|c|}{$\begin{array}{l}\text { Respondents in ECP group } \\
(\mathrm{n}=940)\end{array}$} & \multicolumn{2}{|c|}{$\begin{array}{l}\text { Respondents in abortion } \\
\text { group }(n=1592)\end{array}$} & \multirow[t]{2}{*}{ p-value } & \multirow[t]{2}{*}{ OR $(95 \% \mathrm{Cl})^{\ddagger}$} \\
\hline & $\mathbf{n}$ & $\%$ & $\mathbf{n}$ & $\%$ & & \\
\hline \multicolumn{7}{|l|}{ Demographic characteristics } \\
\hline Age & \multicolumn{2}{|c|}{$21.3 \pm 4.0$} & \multicolumn{2}{|l|}{$28.0 \pm 5.1$} & \multicolumn{2}{|l|}{$<0.001$} \\
\hline Urban residency & 756 & 80.4 & 954 & 59.9 & $<0.001$ & $2.75(2.27-3.32)$ \\
\hline Living with a partner & 43 & 4.6 & 790 & 49.6 & $<0.001$ & $0.05(0.03-0.07)$ \\
\hline \multicolumn{5}{|l|}{ Educational level } & \multicolumn{2}{|l|}{ n.s. ${ }^{*}$} \\
\hline - Primary & 165 & 17.6 & 298 & 18.7 & & \\
\hline - Secondary & 509 & 54.1 & 858 & 53.9 & & \\
\hline - Tertiary & 266 & 28.3 & 436 & 27.4 & & \\
\hline Previous induced abortion & 183 & 19.5 & 885 & 55.6 & $<0.001$ & $0.19(0.16-0.23)$ \\
\hline Previous birth & 157 & 16.7 & 557 & 35.0 & $<0.001$ & $0.37(0.30-0.45)$ \\
\hline \multicolumn{7}{|c|}{ Contraceptive failure at unprotected intercourse leading to ECP use or pregnancy termination ${ }^{\dagger}$} \\
\hline Combined oral contraceptive & 103 & 11.0 & $102+88$ & 11.9 & n.s. ${ }^{*}$ & $0.91(0.70-1.17)$ \\
\hline Progesterone-only pill & 6 & 0.6 & $18+16$ & 2.0 & 0.006 & $0.31(0.13-0.75)$ \\
\hline Intrauterine device & 0 & 0 & 50 & 3.1 & $<0.001$ & $1.03(1.02-1.04)$ \\
\hline Contraceptive ring & 0 & 0 & $1+8$ & 0.6 & 0.031 & $1.01(1.01-1.01)$ \\
\hline Contraceptive patch & 0 & 0 & 1 & 0.1 & n. s. ${ }^{*}$ & $1.00(0.9-1.01)$ \\
\hline Contraceptive injection & 0 & 0 & 1 & 0.1 & n. s. ${ }^{*}$ & $1.00(0.9-1.01)$ \\
\hline Condom & 558 & 59.4 & $216+205$ & 26.4 & $<0.001$ & $4.06(3.42-4.82)$ \\
\hline Withdrawal & 110 & 11.7 & $94+273$ & 23.1 & $<0.001$ & $0.44(0.35-0.56)$ \\
\hline Periodic abstinence & 28 & 3.0 & $191+254$ & 28.0 & $<0.001$ & $0.08(0.05-0.12)$ \\
\hline No method & 135 & 14.4 & 68 & 4.3 & $<0.001$ & $3.76(2.77-5.09)$ \\
\hline Spermicides & 0 & 0 & 5 & 0.3 & n.s. ${ }^{*}$ & $1.01(1.0-1.01)$ \\
\hline Vaginal douche & 0 & 0 & 1 & 0.1 & n. s. ${ }^{*}$ & $1.00(0.9-1.01)$ \\
\hline
\end{tabular}

$\dagger$ Patient failures are grouped according to WHO guidelines on ECP use [4,5] in the ECP group, and contraceptive method use is distinguished as patient + method failures (when appropriate) in the termination of pregnancy sample.

$¥$ OR: Odds ratio, $95 \%$ Cl: $95 \%$ confidence interval.

* n. s.: Statistically not significant.

Table 2 ECP-related questions answered by women attending for an ECP prescription (ECP group, $n=940$ ) or requesting pregnancy termination ( $n=1592$ ) at the Department of Obstetrics and Gynecology, University of Szeged, Hungary (January 1, 2005 - November 20, 2006).

\begin{tabular}{|c|c|c|c|c|c|c|}
\hline & \multicolumn{2}{|c|}{$\begin{array}{l}\text { Respondents in ECP group } \\
(\mathrm{n}=940)\end{array}$} & \multicolumn{2}{|c|}{$\begin{array}{l}\text { Respondents in abortion } \\
\text { group }(n=1592)\end{array}$} & \multirow[t]{2}{*}{ p-value } & \multirow[t]{2}{*}{ OR $(95 \% \mathrm{Cl})^{\dagger}$} \\
\hline & $\mathbf{n}$ & $\%$ & $\mathbf{n}$ & & & \\
\hline \multicolumn{7}{|c|}{ Questions relating to the knowledge, attitudes, and use of ECP } \\
\hline Awareness of ECP & 940 & 100 & 1400 & 87.9 & $<0.001$ & $1.14(1.12-1.16)$ \\
\hline Previous ECP use & 310 & 33.0 & 501 & 31.5 & n.s.* & $1.07(0.9-1.27)$ \\
\hline $\begin{array}{l}\text { Knowledge of time limit for ECP treat- } \\
\text { ment }\end{array}$ & 732 & 77.9 & 939 & 59.0 & $<0.001$ & $2.45(2.04-2.94)$ \\
\hline Knowledge of how to obtain ECP & 742 & 78.9 & 319 & 20.0 & $<0.001$ & $14.9(12.2-18.2)$ \\
\hline Good knowledge of ECP¥ & 594 & 63.2 & 682 & 42.8 & $<0.001$ & $2.3(1.9-2.71)$ \\
\hline Intended future ECP use & 634 & 67.4 & 1212 & 76.1 & $<0.001$ & $0.65(0.54-0.77)$ \\
\hline
\end{tabular}

$\dagger$ OR: Odds ratio, $95 \% \mathrm{Cl}$ : $95 \%$ confidence interval.

$¥$ Appropriate knowledge of ECP: awareness of how to obtain ECP and when it must be taken after unprotected intercourse, i.e, both questions were correctly answered [8]

* n. s.: Statistically not significant.

ECP group vs. $20.0 \%$ in the abortion group, $\mathrm{p}<0.001$ ) were also significantly more favorable among ECP users. A positive attitude toward ECP use was generally expressed in both groups, despite the fact that many abortion seekers $(n=759)$ had not realized the need for ECP (this amounts to $48 \%$ as patient failures that might have been avoided through the use of ECP). The women who presented for abortion and who had previously used ECP were asked about the reason for not using it this time: the most important motivations were that they had not realized the need for using
ECP and the neglect of the possibility of conception (data are not shown in table), as described in a Swedish study $[9,10]$.

\section{Source of information for ECP}

- Table 3 lists the data relating to the acquisition of information regarding ECP. The sources of information were significantly different in the two groups; the media, friends and health-care providers were identified as the main sources of information concerning ECP by most respondents. 


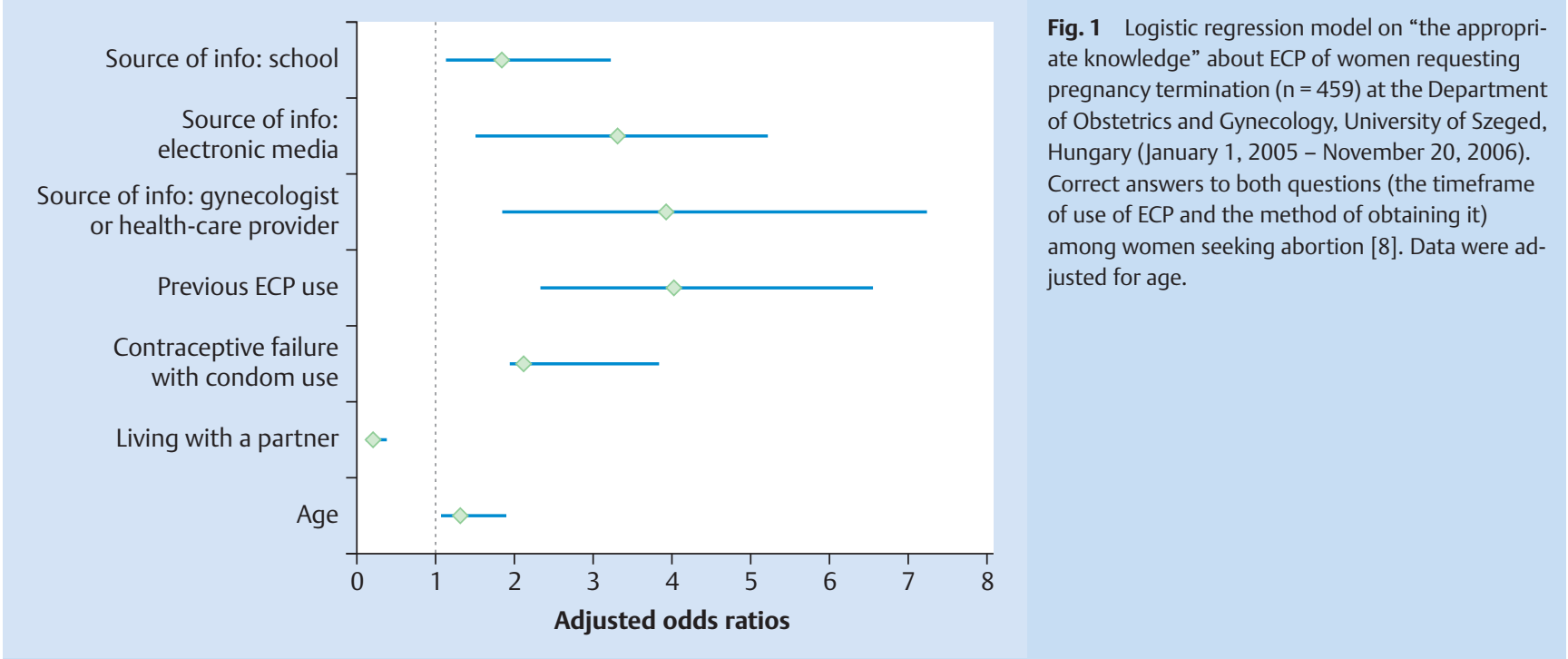

Table 3 Source of information regarding ECP of women attending for an ECP prescription (ECP group, $n=940$ ) or requesting pregnancy termination ( $n=1592)$ at the Department of Obstetrics and Gynecology, University of Szeged, Hungary (January 1, 2005 - November 20, 2006).

\begin{tabular}{|c|c|c|c|c|c|c|}
\hline & \multicolumn{2}{|c|}{$\begin{array}{l}\text { Respondents in ECP group } \\
(\mathrm{n}=940)\end{array}$} & \multicolumn{2}{|c|}{$\begin{array}{l}\text { Respondents in abortion } \\
\text { group ( } n=1592 \text { ) }\end{array}$} & \multirow[t]{2}{*}{ p-value } & \multirow[t]{2}{*}{ OR $(95 \% \mathrm{Cl})^{\dagger}$} \\
\hline & $\mathbf{n}$ & $\%$ & $\mathbf{n}$ & $\%$ & & \\
\hline \multicolumn{7}{|c|}{ Source of information for ECP } \\
\hline Friends & 442 & 47.0 & 588 & 42.0 & 0.02 & $1.23(1.04-1.45)$ \\
\hline Family & 123 & 13.1 & 20 & 1.4 & $<0.001$ & $10.4(6.42-16.8)$ \\
\hline Sexual partner & 70 & 7.4 & 8 & 0.6 & $<0.001$ & $14.0(6.70-29.8)$ \\
\hline Gynecologist & 138 & 14.7 & 712 & 50.9 & $<0.001$ & $0.17(0.13-0.20)$ \\
\hline Other health-care providers & 386 & 41.1 & 235 & 16.8 & $<0.001$ & $3.45(2.85-4.18)$ \\
\hline Printed media & 208 & 22.1 & 25 & 1.8 & $<0.001$ & $15.6(10.22-23.8)$ \\
\hline Electronic media & 630 & 67.0 & 944 & 67.4 & n.s. ${ }^{*}$ & $0.98(0.82-1.17)$ \\
\hline School, education & 208 & 22.1 & 19 & 1.4 & $<0.001$ & $20.6(12.8-33.3)$ \\
\hline
\end{tabular}

○R: Odds ratio, $95 \% \mathrm{Cl}$ : $95 \%$ confidence interval.

¥ Source of information was asked from those who had ever heard of ECP $(n=1400)$ in the termination of pregnancy group.

* n. s.: Statistically not significant.

\section{Appropriate knowledge about ECP}

\section{of women requesting pregnancy termination}

Multivariate logistic regression analysis revealed that previous ECP use (adjusted odds ratio [AOR]: 4.01, 95\% CI: 2.31-6.54) and the information primarily obtained from electronic media (AOR: 3.29, 95\% CI: 1.48-5.20), health-care providers (AOR: $3.91,95 \%$ CI: $1.83-7.22$ ) and sexual education in school (AOR: $1.83,95 \%$ CI: 1.11-3.21) promoted "the proper knowledge" of ECP usage among the abortees most significantly. The contraceptive failure with a condom was also related to a higher knowledge of the correct management of access to ECP (AOR: 2.1, 95\% CI: 1.83-3.82). Higher age (AOR: 1.3, 95\% CI: 1.05-1.89) and living without a partner (AOR: 5.55, 95\% CI: 2.77-9.09) made the awareness of the correct management of ECP use more likely ( $\bullet$ Fig. 1).

\section{Discussion}

Our more striking results are that ECP users favor different contraceptive methods (predominantly barrier method, withdrawal and patient failure with OC) than abortion seekers (periodic ab- stinence, withdrawal and condom) which reflect mainly the different sociodemographic characteristics of the groups. The contraceptive patterns of ECP users in Hungary differ in Germany where ECP is prioritized mainly after an unprotected intercourse (55\%), condom failure (34\%) and method failure of OC usage (10\%) [11]. ECP proved to be preferred by young women in our region as in Germany [11], but in contrast with the finding of Sørensen et al. [12] that ECP users were generally older than women with an unwanted pregnancy after unprotected intercourse. Furthermore, education was not a distinguishable factor in opting for ECP, likewise in contrast with the conclusion of the Danish study [12]. Moreover, abortion seekers were more likely to be unaware of ECP as a backup method and were not well informed upon the availability of the ECP, whereas more ECP users lived in an unstable relationship. By contrast, previous use of ECP was of similarly low prevalence in the two groups.

Gaining information from reliable sources (education, healthcare providers and media campaigns) was an important influential factor promoting a good knowledge about the management of ECP use, which seems to be in contrast with the literature findings $[13,14]$. It seems that condom users know the correct em- 
ployment of the ECP as in a French study [15], and they commonly live without a partner (503 out of 558 [90.1\%] lived without a spouse, not presented in the tables). Our logistic regression demonstrated that correct knowledge of ECP was promoted by a higher age and previous ECP use.

The prescription status of ECP might act as a moderate obstacle to access ECP in Hungary in view of the small number of abortion seekers who had administered it. Interestingly, almost half of the abortion seekers (43\%) experienced a contraceptive failure that might have been avoided if they had sought ECP (i.e. patient failure of the contraceptives), even though the vast majority (87.9\%) were aware of ECP, as in other countries $[8,12,16,17]$, and nearly one-third of them (31.5\%) might even have been able to prevent a contraceptive mishap since they used ECP before. Although the female population requesting abortion in Hungary [7] is aware of the ECP, specific knowledge of the time span between unprotected intercourse and access to ECP usage is rather poor among women who sought abortion, as in Sweden [9]. Altogether, these data suggest that more effective and individual contraceptive counseling is required after abortion, exploring factors associated with the contraceptive problem. Such tailored counseling including advice on future ECP use should focus on contraceptive mishaps appropriate for seeking ECP, timing-related efficacy of ECP use after unprotected intercourse and the awareness about the procedure to obtain the drug, since $76 \%$ of the abortion seekers intended to use it in the future, but only $20 \%$ knows how to receive it. Similarly, Siebert and Steyn found that women requesting pregnancy termination were on average highly educated, but had a poor knowledge of ECP and were ill-informed about contraception, while teenagers were most at risk [12].

Failure rate of ECP in our study was only $1.38 \%$ (13 out of 940 ), which corresponds to a literature finding (1.5\%) [5].

As in a Swedish study [9], discussions with health-care providers and the electronic media may promote more preventive behavior, and apart from this, health education at school is cited very frequently in Hungary. Other potential sources should therefore be concentrated on, so as to increase public awareness and the use of ECP.

Apart from limited access, the obstacles to ECP use such as low awareness and doubtful attitudes have been eliminated, but the predominant persisting obstacle is the unawareness of the risk of pregnancy. The main outcome of our study is that the recognition of the need for ECP by the patients seeking abortion is strikingly deficient, as reported by other authors [9].

\section{Conclusions for Clinical Practice}

$\nabla$

Only few abortion seekers had used ECP and they did not recognize the need of the ECP in most of the cases, even though they were aware of it and had a positive attitude towards it. Like Larsson et al. [9], we suggest that new contraceptive counselling strategies should be developed for women presenting for induced abortion, providing them with the details of appropriate ECP use so as to avoid unwanted pregnancy in the future.

It would be beneficial to improve public knowledge about the timing-related efficacy of the ECP and the contraceptive failures for which ECP can be used. A specific media campaign is required, targeting women of advanced age and who have experienced a previous unwanted pregnancy, focusing on the fertility risk with contraceptive failure and the usefulness of ECP.

\section{Conflict of Interest}

$\nabla$

None of the authors has a political, personal, intellectual, commercial, financial or religious conflict of interest, and/or other relation to manufacturers of pharmaceuticals, laboratory supplies and/or medical devices or to commercial providers of medically related services.

\section{References}

1 Hungarian Central Statistical Office. Demographic Year Book. Budapest: Hungarian Central Statistical Office; 2010 (in Hungarian)

2 Sedgh G, Bankole A, Singh S et al. Legal abortion levels and trends by woman's age at termination. Int Perspect Sex Reprod Health 2012; 38: $143-153$

3 David M, Berends L, Bartley J. Current opinion of obstetricians on the prescription of emergency contraception: a German-American comparison. Geburtsh Frauenheilk 2012; 72: 1004-1008

4 WHO - World Health Organization. Emergency contraception. Online: http://www.who.int/mediacentre/factsheets/fs244/en/; last access: 20.03.2016

5 von Hertzen H, Piaggio G, Ding J et al. WHO Research Group on Postovulatory Methods of Fertility Regulation. Low dose mifepristone and two regimens of levonorgestrel for emergency contraception: a WHO multicentre randomised trial. Lancet 2002; 360: 1803-1810

6 Glasier A, Fairhurst K, Wyke S et al. Advanced provision of emergency contraception does not reduce abortion rates. Contraception 2004; 69: 361-366

7 Kozinszky Z, Bártfai G. Contraceptive behaviour of teenagers requesting abortion. Eur J Obstet Gynecol Reprod Biol 2004; 112: 80-83

8 Perslev A, Rorbye C, Boesen HC et al. Emergency contraception knowledge and use among Danish women requesting termination of pregnancy. Contraception 2002; 66: 427-431

9 Larsson M, Aneblom G, Eurenius K et al. The adoption of emergency contraceptive pills in Sweden: a repeated cross-sectional study among abortion applicants. Acta Obstet Gynecol Scand 2006; 85: 1142-1143

10 Aneblom G, Larsson M, Odlind V et al. Knowledge, use and attitudes towards emergency contraceptive pills among Swedish women presenting for induced abortion. Br J Obst Gynaecol 2002; 109: 155-160

11 David M, Radke AM, Pietzner K. The prescription of the morning-after pill in a Berlin emergency department over a four-year period - user profiles and reasons for use. Geburtsh Frauenheilk 2012; 72: 392-396

12 Sørensen MB, Pedersen BL, Nyrnberg LE. Differences between users and non-users of emergency contraception after a recognized unprotected intercourse. Contraception 2000; 62: 1-3

13 Siebert I, Steyn PS. Knowledge and use of emergency contraception in a tertiary referral unit in a developing country. Eur J Contracept Reprod Health Care 2002; 7: 137-143

14 Harvey M, Beckman LJ, Sherman C et al. Experience and satisfaction with emergency contraception. Fam Plann Perspect 1999; 31: 237240,260

15 Goulard H, Moreau C, Gilbert F et al.; Cocon Group. Contraceptive failures and determinants of emergency contraception use. Contraception 2006; 74: 208-213

16 Lee SWH, Wai MFY, Lai LYH et al. Women's knowledge of and attitudes towards emergency contraception in Hong Kong: questionnaire survey. Hong Kong Med J 1999; 5: 349-352

17 Moodley J, Morroni C. Emergency contraception: lack of awareness among women presenting for termination of pregnancy. S Afr Med J 2007; 97: 584-585 